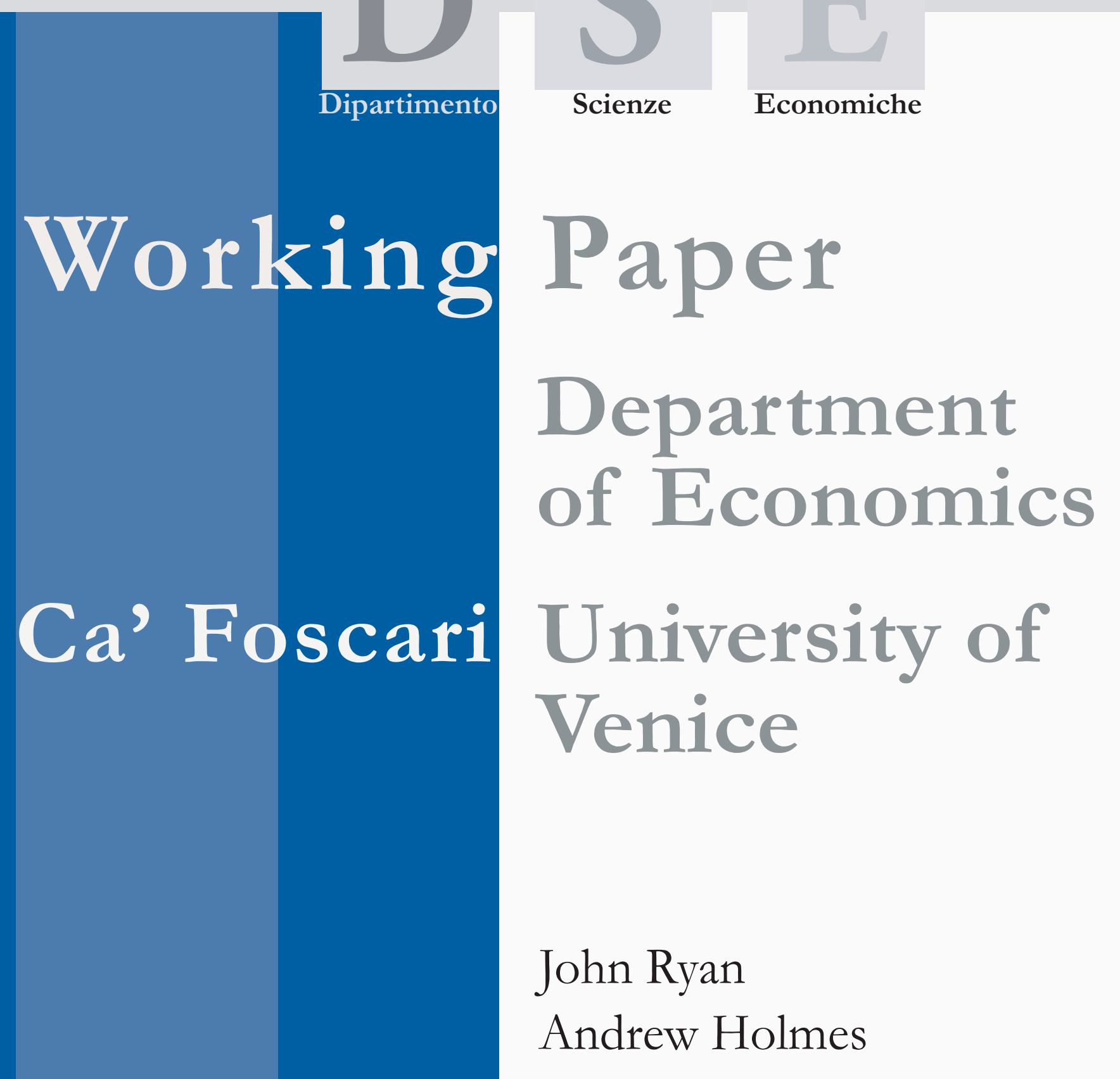

Economic and Business

Responses to the Pressures of Commoditization 


\title{
Economic and Business Responses to the Pressures of Commoditization
}

\author{
John Ryan \\ Hult International Business School \\ Andrew Holmes \\ Partner, Paricint
}

\begin{abstract}
This paper examines the pressures of commoditization will continue to exert itself on companies and managers everywhere: the increasing impact of demographic change; the requirement to maintain a keen eye on costs in order to compete effectively within the global market; the continued advance of technology; the ability to standardize processes and eliminate major inefficiencies; the pressure to outsource and offshore business activities in order to exploit the cost advantages of cheaper labour and the opportunity for your competition to attack your markets and replicate your products and services more freely.

Tackling commoditization in a fragmented or short-termist way will not allow you to understand its effects and nor will it provide the solid platform required to build an effective response. So when it comes to considering the potential impacts of commoditization you need to ask yourself the following two questions:

1. Can all or part of our business become commoditized? It is easy to believe that you are immune to the effects of commoditization and that you don't need to respond to something that may not even be on your horizon. When responding to this question the best approach is to start from the position that everything you do is capable of becoming commoditized if not now, then certainly at some point in the future. Of course you may find that not everything can be commoditized, but it is far better to come to this conclusion after completing a thorough analysis of your business than making assumptions based upon a limited perspective or worse still, gut feel

2. How should we respond to the threat of commoditization? In particular should we embrace it or avoid it? This is a crucial question to answer once you have understood the threats and opportunities commoditization poses to the organization. As with any strategic decision it is likely to have significant operational implications. In some cases you may find that you have little alternative but to become more commoditized yourself, whilst in others you may be able to adopt a more flexible approach. When considering the response, you will need to think about such things as:

- How can we insulate ourselves from the threat of commoditization?

- $\quad$ Given the choice what parts of our business should we allow to become commoditized?

- Where and in which markets should we innovate as a way of avoiding the commoditization trap?

- Where should we target our investments - with our customers, on our back office processes, in research and development, on acquisitions or all of the above?
\end{abstract}

\section{Keywords}

Commoditization, Offshoring, Talent, Technology, Competition, Inequality

JEL Codes

A10, D21, D23, D24, D40, F02

\author{
Address for correspondence: \\ John Ryan \\ Flat 7, 307 Upper Richmond Road, \\ London SW15 6SS - England \\ Phone: (++44) 7951765549 \\ jmtryan@aol.com
}

This Working Paper is published under the auspices of the Department of Economics of the Ca' Foscari University of Venice. Opinions expressed herein are those of the authors and not those of the Department. The Working Paper series is designed to divulge preliminary or incomplete work, circulated to favour discussion and comments. Citation of this paper should consider its provisional character

The Working Paper Series is availble only on line (www.dse.unive.it/pubblicazioni) For editorial correspondence, please contact: wp.dse@unive.it
Department of Economics

Ca' Foscari University of Venice

Cannaregio 873, Fondamenta San Giobbe

30121 Venice Italy

Fax: ++390412349210 


\section{What to do when faced with low cost competition}

Taking a deliberate strategy of competing on cost is always simpler when starting a new business or moving into a known commoditized market, but what options should be considered in those organizations that are facing the prospect of competing with low cost rivals? One thing is clear and that is ignoring them is a recipe for disaster as it usually forces the incumbent to vacate entire market segments principally because the low cost rival is able to completely change consumer behaviour ${ }^{1}$. There are three options open to organizations when faced with price cutting competitors. First they can differentiate their products so that consumers are willing to pay a premium over and above those offered by their cost focused rivals. This can be achieved through a number of ways including continuous innovation such as Gillette do with their shaving products or designing cool products and offerings as Apple continue to do with their IMac and IPod product ranges ${ }^{2}$.

Second they can set up a low cost subsidiary to compete head-to-head with their low cost competition. In this instance it is essential to use the same tricks used by the low cost rival, focus on making money, avoid attacking the principal business' markets and achieve synergies between the mainstream business and the low cost subsidiary. British Airways failed to leverage its low cost airline Go because it kept it separate and lost the natural synergies that would have resulted had it been more integrated with its parent; it was eventually sold to Easy Jet.

The third option involves changing the business model to address the threat. There are two choices here. The first is to switch from products to solutions and this is what many corporations decide to do when faced with the threat of low cost competition. The problem with this is that the switch from a product to a service focused business is not that simple and in fact can be highly damaging as Xerox found when it attempted to promote itself as a document solutions business. And for those organizations which have managed to transform, the process has been difficult as we saw when IBM had to restructure and reengineer its business in response to the rise of Microsoft and the shift away from mainframe computers ${ }^{3}$. Dell is finding that it too is having to respond to a change in market sentiment as consumers shift to using laptops and retail prices for technology products continue to slump. With Michael Dell back at the helm after ousting chief executive Kevin Rawlins, shareholders hope that he will return the company to its glory days ${ }^{4}$. Successful transformation necessitates a near 180 degree change in direction and recognition that the approach to building and selling solutions is very different to building and selling products. Most critically, it is essential to understand the fundamental difference between a product and service focused business. A product focused business tends to start with the products and then seeks ways to match these to customers' needs and when customers want something new an additional feature is added to the product to satisfy that need. The reverse is true of a solutions based approach which begins with the desired outcome before developing the solution to meet that need. Being successful at selling solutions also requires greater integration and transparency with others in the supply chain and

\footnotetext{
${ }^{1}$ Kumar, N., (2006), Strategies to fight low-cost rivals, Harvard Business Review, December, p 106

2 Ibid, p 109

${ }^{3}$ Foote, N., et al., (2001) Making solutions the answer, The McKinsey Quarterly, Number 3

${ }^{4}$ The Business (2007), Dell needs a boy wonder, February 10, p 32.
} 
changing the customer base, which often means dropping existing customers and seeking out new ones, perhaps outside of the traditional market ${ }^{5}$.

Key to success is the near complete transformation of the business from the front office through to the back which has to encompass the skills and capabilities of the workforce as well as the many other strands of the organization such as channel strategies, suppliers, and management behaviour, all of which can be incredibly uncomfortable. The second approach to changing the business model is to beat the low cost competitors at their own game by becoming one yourself, but this is even more difficult to achieve than moving to a solutions or pure services based organization and few companies have been successful.

\section{Areas to consider when developing your response}

With the impacts of commoditization being so wide ranging, organizations have a variety of means through which they can respond, including:

- Process simplification and optimisation

- Cost containment and management

- Outsourcing and offshoring

- Supply chain management

- Talent management and labour management

- Innovation

- Branding.

When looking down this list it becomes clear that there are two broad thrusts to the response. The first is to have a cost and efficiency focus and the second is to have a value creation focus. The two should go hand in hand as concentrating purely on cost and efficiency can lead to problems downstream, as we saw with the business process reengineering movement of the 1990s. Although many of the areas listed above are potentially relevant to every organization, it is their relative importance that is important here, as some will be more essential and indeed more relevant than others.

\section{Process simplification and optimisation}

There are six steps towards total process commoditization (Figure 1) and each brings greater benefits because the more a process is standardised and commoditized the greater the savings in time and headcount will be. The process through which this is achieved is not completely linear, as there are opportunities to revisit the earlier steps as clarity around the process increases.

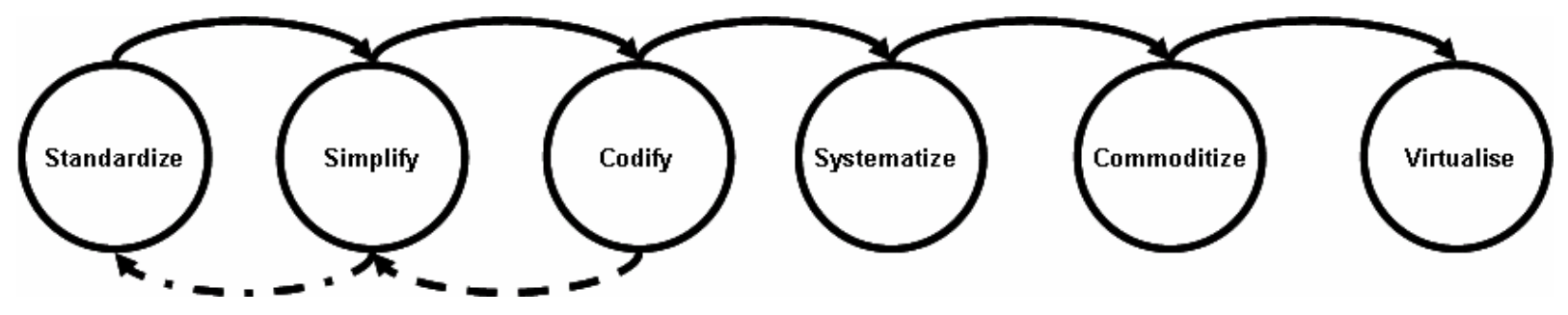

Figure 1 - achieving process commoditization

1. Standardize. In a commoditized business the need for standardized processes is particularly important because significant savings can be made through the removal of redundant steps associated with localised processes and unnecessary

\footnotetext{
${ }^{5}$ Foote, N., et al., (2001) Making solutions the answer, The McKinsey Quarterly, Number 3, pp 87-88
} 
human intervention.

2. Simplify. One you have a standardized set of processes you should be aiming to simply them as much as possible. Although many companies attempt to standardize and simplify simultaneously, it is better to standardize first because it is generally easier to simplify a standard process than a collection of non-standard processes. The simplification approach typically involves getting into the detail of the processes and the business activities which they support.

3. Codify. The ability to codify and make visible the intricacies of industrial and human processes is key to allowing them to become fully commoditized. Making processes transparent and easily understood by everyone allows you to both reduce the reliance on the experts who may have been involved with the execution of the process in the past and also to widen the pool of resources who can execute the work going forward.

4. Systematize. As this step suggests, to achieve further process efficiencies it is necessary to use technology. Technology has been eliminating manual processes ever since it took hold during the Industrial Revolution and will continue to remove human contact from work processes as these become more simplified and codified. Once a process is sufficiently transparent and standardised the opportunity to then automate it increases significantly.

5. Commoditize. Once you have systematized your processes you are then in a position to commoditize them. Treating your processes as a commodity provides you with more choices and flexibility over who should manage and execute them and allows you to compare the costs of their execution more readily. In other words it allows the process to become independent of its execution.

6. Virtualize. This should be the ultimate aim of any focus on process and where the greatest benefits lie. At this level you should have the confidence that no matter who executes the process or where it is executed, it will produce consistently reliable results. This opens up the opportunity to fully outsource the execution of the processes either to a local supplier or offshore it to another country, such as India.

\section{Cost containment and cost management}

The management of costs is an issue for every organization. Whether a global major or a small localised manufacturer, every business has to worry about the costs it incurs to deliver their products and services into their chosen markets. Despite this common need to control costs, organizations struggle to establish a permanent cost management ethos amongst their workforce. We only need to witness the periodic cost cutting that takes place to understand that few are really expert at maintaining an effective balance between cost control and the more laissez faire attitude to cost management. Although some of this may be due to sudden changes in fortune or the impacts of a changing economic cycle, most of it is down to the difficulty companies face in trying to keep a lid on costs, especially those associated with labour.

Although all organizations across the commoditization spectrum have to be competent at managing their costs, it is those within the commoditized zone that have to place a much greater significance on cost management because failure to address the underlying cost base can mean the difference between a market leading position and operating within the knife-edge conditions of near bankruptcy. Indeed this is beginning to be the case within the IT outsources service providers who increasingly have to address the risks associated with razor thin margins. Those that are able to address their internal costs will outperform those that can't, as the one thing you come 
to realise is that there is always someone else out there who is willing to compete on price.

Addressing the cost issue has to start with an understanding of the types of costs which the business is incurring be they production, trading or operating costs; direct or indirect; capital; employee and so on. It is also essential to get a clear picture of costs by each functional area so that it is possible to model how the costs of the function translate into outcomes and ultimately the bottom line. The use of benchmarking and activity based costing can be very helpful in this respect.

Companies which operate within the commoditized zone have a ruthless focus on cost so that any cost is focused on adding value to the delivery of the products or services they provide to their customers. Take the low cost airlines as one example. In order for Easyjet and Ryanair to compete against the major carriers they had to redefine the nature of air travel so that their customers were willing to accept fewer frills and addons in return for very cheap fares. Easyjet was one of the first airlines to go completely ticketless and Ryanair has recently reduced the baggage allowance for their customers and will be charging them for items which fall outside of the allowance. All of this is designed to reduce costs so that they can maintain some of the lowest fares in the industry. It should come as no surprise that every nickel and dime saved helps to maintain a profitable business and what is fascinating about the low cost airline model is that customers are willing to put up with the reduced comfort and service levels.

\section{Outsourcing and offshoring}

When thinking about the opportunities which outsourcing and offshoring present it is important to consider how far you want to go. Whilst in the past much of the outsourcing and offshoring was aimed at the lower order activities, such as call centres, today there is a lot more on offer and the option to outsource high end activities is now possible. The best way to view this is as a range from low to high value activities as below ${ }^{6}$ :

- Low value - call centres and basic order processing

- Medium value - accounting, interpretation of X-rays, graphics

- Medium to high value - engineering, insurance claims

- High value - underwriting, equity research, market research.

This shift reflects the general changes in how outsourcing is now perceived. Although in the past it was considered a tactical move to tackle costs or a difficult organizational function, principally IT, it is now considered to be part of the strategic armoury which organizations can use to address their market position.

To those who wish to investigate and pursue the outsourcing agenda. First it is vital to understand why you are pursuing outsourcing and offshore route in the first place and to ensure the necessary debates have been had with the principal stakeholders and decision makers. Second, it is necessary to determine how far up the process value chain you wish to proceed and this depends on how the board both perceives the threats and opportunities associated with commoditization and how it defines its response. Third nearshoring opportunities should be considered when seeking an offshored solution. Nearshoring offers some advantages over the fully offshored model including: cultural affinity; better language skills; a reduction in trade associated costs (by remaining within a single trading bloc, such as NAFTA for

\footnotetext{
${ }^{6}$ These categories have been derived from a lecture delivered by Dr. Jeffery Sampler of Oxford University 7-9 March 2005
} 
example); security and legal protection; improved control and ease of intervention should issues arise and reduced impacts of time zone differences ${ }^{7}$. Fourth, if considering going completely offshore it is important to take your time to select the right country to offshore to, as mistakes can be very costly. Such things as supply of the right labour, prevailing salaries, cultural variations and differences, the level of geopolitical risk, the level of sophistication of the services offered within the country and their experience and expertise in managing offshored business processes all need to be considered before arriving at the decision ${ }^{8}$. And finally make sure you follow a tried and tested process, supported by experts in the area of contract negotiation, service management and who have had prior experience of helping organizations outsource their processes.

\section{Supply chain management}

Supply chain management is a concept that came into vogue around 20 years ago to crystallise the idea of managing an organization in terms of the resources, activities and strategies of those companies on which it depends ${ }^{9}$. Viewed in simple terms the supply chain links the organization and its processes to its suppliers at one end of the chain (who provide raw materials, semi-finished products and so on) and the customer at the other. This belies the underlying complexity of many supply chains which can be difficult to unravel and are rarely linear. However, as a concept it is increasingly important as it is often viewed as a strategic process within organizations and especially those which have a global footprint. Building a strong supply chain is considered to be an essential component of business success ${ }^{10}$ and as organizations grapple with low cost competition and a commoditized market, the requirement to make the supply chain work as smoothly as possible is a very real one. This is not a simple task as it requires the involvement of suppliers who have to be intimately involved with any changes because there has to be mutual benefits otherwise it is unlikely they would want to play ball.

When it comes to addressing the supply chain it is recommended that you follow a three step process ${ }^{11}$. Step one involves understanding the supply chain itself, its internal dynamics, characteristics and relationships. There are some 15 dimensions along which the supply chain can be defined and understood, including the product life cycle, the number of channels and the material flow, the volume per order/product and the mix of products in terms of movement, costs and inventories ${ }^{12}$. Having mapped, modelled and understood the supply chain the next thing to do is to build in the operational and management practices so that it is efficient and effective. Such operational and management practices include data integrity, enterprise-wide demand and supply management and building lean processes. Once this step is completed and

\footnotetext{
${ }^{7}$ Brown, R., and Karamouzis, F., (2005) Assess the 'Nearshore' advantages for business process outsourcing, Gartner, September 12,

${ }^{8}$ Marriott, I., (2005) Consider offshore options around the globe, Gartner, June 13.

${ }^{9}$ Lamming, R, (2001), The Financial Times handbook of management (second edition), (London: Financial Times Prentice Hall), p 398

${ }^{10}$ Lee, H., (2006) The triple-A supply chain, Harvard Business Review on Supply Chain Management, (Boston Massachusetts: Harvard Business School Publishing), p 87

${ }^{11}$ Tyndall, G., et al, (1998) supercharging supply chains, (New York: John Wiley \& Sons Inc.), pp 238-241

${ }^{12}$ For the full list of the 15 dimensions, see Tyndall, G., et al, (1998) supercharging supply chains, (New York: John Wiley \& Sons Inc.), p 238.
} 
the supply chain is stable you can then begin to innovate around it by exploring other means of enhancing it and making it even more effective. The purpose behind all this is to have a supply chain that is agile (capable of responding to abrupt changes in market conditions), adaptable (collecting and tracking key data that identifies trends and patterns which may require a response) and aligned (the interests of the organization and its suppliers are fully aligned) ${ }^{13}$. When in place the triple A (agile, adaptable and aligned) supply chain can provide a strategic advantage over rivals in so far as it is easier to:

- Respond to new demands and get new products to market

- Adapt to crises and interruptions due to war and natural disasters and recover much faster

- Adjust to structural changes in the supply networks which arise from political, economic, demographic and social change

- Run multiple supply chains to meet the needs of particular market segments.

\section{Talent and labour management}

A recent survey by Towers Perrin, the global professional services firm, found that only 11 per cent of European employees considered themselves to be highly engaged at work; some 22 per cent were disengaged and the remaining 67 per cent were moderately engaged ${ }^{14}$. Compared to the wider data, Europe comes out quite well as the Asia Pacific region has, surprisingly, a greater problem with engagement; compared to North and South America however, Europe lags considerably ${ }^{15}$. Engagement is important because it is the engaged employee who is willing to go the extra mile, who believes in the organization's mission and who believes what senior executives say. In short this 11 per cent are the people who believe they make a difference. Moreover they are less likely to leave or consider leaving if made a better offer by another employer - 65 per cent have no intention of leaving against the mere 15 per cent of disengaged workers ${ }^{16}$. Some of the problems associated with engagement can be put down to the psychological contract which still retains its importance despite the impacts of the business process reengineering zealots of the 1990s. It is well known that when employees feel that their boss or company has broken their expectations about work or career opportunities they typically feel less committed. When this happens, engagement dips, morale falls and the willingness to put in the extra effort that makes a difference vanishes ${ }^{17}$. We then end up with the issues raised by David Bolchover in his book the Living Dead - staff surfing the net, running businesses from their desks, emailing their friends and socialising with their work colleagues ${ }^{18}$. In fact doing everything else but work!

As commoditization strengthens its grip the problems associated with engagement and the psychological contract will increase. Presented with problems such as these, what is HR to do? Naturally focusing on the highly talented amongst the rank and file is important, but failing to address the motivational issues of the also ran's, and those who although not destined for great things, are still critical to the success of the

\footnotetext{
${ }^{13}$ Lee, H., (2006) The triple-A supply chain, Harvard Business Review on Supply Chain Management, (Boston Massachusetts: Harvard Business School Publishing), p 88

${ }^{14}$ Ibid., p 4

15 Ibid., p 5.

${ }^{16}$ Ibid., p 10.

${ }^{17}$ CIPD (2002), Sustaining success in difficult times, p 1.

${ }^{18}$ Bolchover, D., (2005) The Living Dead: Switched off, Zoned out the shocking truth about office life, (Chichester: Capstone)
} 
business is going to be fatal. So organizations are not only going to have to get smarter at winning the talent wars, but they are also going to have to get better at keeping the commoditized worker engaged. Both are important and both require an appropriate response, and HR will need to rise to the challenge.

\section{Winning the talent wars}

The war for talent, which following the collapse of the Dot Com boom conveniently went away is now coming back with a vengeance as the population ages and the number of new workers begins to fall short of the numbers required to run an efficient organization. Immigration may help but there are three reasons why this may not be the panacea that many, including politicians, believe it to be. First, despite the fact that immigration has helped to keep inflation low in much of the industrialised West, the ability to sustain this over the medium term is doubtful as it will require wave after wave of fresh immigrants. ${ }^{19}$ Furthermore, immigration will not prevent populations from aging, as it is well known that immigrant communities will over time, drift to their host nation's birth rates ${ }^{20}$. So although they may prefer larger families on arrival, over time the number of live births regresses to the mean of the country to which they have emigrated. Second, many of the immigrants work at the low end of the economy and entry level positions within organizations which may make them a valuable resource and may help to keep labour costs down, but it does not address the talent issues companies are facing at the strategic level. Finally the qualified immigrants who have traditionally been attracted into the well paid positions are beginning to return home as their native economies expand and the opportunities for well paid employment and entrepreneurship increases ${ }^{21}$.

To win the war for talent, organizations need to do two things. The first is to really understand why talented people move on from their employers and the second is to define challenging and forward looking roles for their best staff. The first is the easy part, whilst the second may be a little harder. Irrespective of where the organization may sit along the commoditization continuum, attracting and retaining talent will be an essential component of the HR strategy.

Before you can begin to manage your talent more diligently, it is a good idea to understand why they leave in the first place. The principal reasons $\operatorname{are}^{22}$ :

- The job or workplace was not as expected, in other words there were unmet expectations on either side

- Mismatch between job and person, where the role the talented employee was given provided limited opportunity for them to use their skills and capabilities.

- Too little coaching and feedback without which it is impossible to keep your talent engaged with the organization's direction and their part in it

- Too few growth and advancement opportunities which will if left unchecked leave the talented employee at best disengaged and at worst seriously thinking about moving on

- Feeling devalued and unrecognised. Increasingly, the most obvious indication the talented employee has of value to their employer is their pay. When this appears

\footnotetext{
${ }^{19}$ Searjeant, G., (2006), Immigrants help to hold down interest rates, Bank report says, The Times, December 11, p 34.

${ }^{20}$ Wagstyl, S., (2007), An important test of tolerance, The world in 2007, Financial Times, 24 January, p 8.

${ }^{21}$ Wonacott., P., (2006) Indian scientists return home as economy moves a step up, The Wall Street Journal, p A1 and A12

${ }^{22}$ Branham, L., (2005), The 7 hidden reasons employees leave, (New York: AMACOM), pp 31-194
} 
inequitable or fails to reflect the going rate for someone of their capability, they will disengage and move on.

- Stress from overwork and work-life imbalance. Stress levels are likely to increase as companies expect more from their most talented employees and reduce the span of control and scope of the work for the remainder of its workforce; no one will be immune.

- Loss of trust and confidence in senior leaders which appears to be a growing concern amongst many workforces.

So what should organizations do to retain their high performing employees? The advice is thick and fast but most tends to boil down to a few hard and fast rules. The first is to talk to them and find out why they stay and what motivates them and what they want to do with their career ${ }^{23}$. Obvious perhaps, but it is rare for a senior executive to ask their subordinates why they turn up day after day. The next thing is to ensure that managers throughout the company take it upon themselves to look after their talented staff, something McKinsey call embracing the talent mindset ${ }^{24}$. This is important because it is the direct manager who has the greatest control and influence over employee perception ${ }^{25}$. This must be accompanied by meaningful discussions about career paths.

\section{Keeping the commoditized worker engaged}

The percentage of talented staff within a commoditized business is typically low as the business does not operate a model which requires vast numbers of them. In fact the business remains profitable by employing great armies of low cost employees and using a combination of outsourcing and offshoring to ensure their cost base remains as low as possible. However, just because there are fewer talented individuals within the organization it doesn't mean you should adopt a laissez faire attitude to the management and development of those that remain. In fact the opposite is true; it is comparatively easy to manage a small talent pool because the majority of those within it are motivated and self starters. Motivating low paid staff who may see working life little more than just a succession of jobs is much, much harder. The problem is that as more companies come to depend on a commodity workforce the issues associated motivation and commitment will become more significant.

According to the authors of The Enthusiastic Employee, there are three primary sets of goals which people want from work - equity, achievement and camaraderie ${ }^{26}$. These three goals are consistent over time and vary little between different groups of workers and for the majority are more important than any other work based goals they might have. Let's look briefly at each of these three areas and consider what it means for the motivation, leadership and management of commodity workers. The first, equity, requires the organization to ensure their workers' physiological, economic and psychological needs are met. Providing a safe working environment, paying your staff a living wage and treating them with respect is a good place to start. Next it is

\footnotetext{
${ }^{23}$ Kaye, B., and Jordan-Evans, S., (1999) Love 'em or lose 'em: getting good people to stay, (San Francisco: Berrett-Koehler Publishers), pp 1-8

${ }^{24}$ Michaels, E., et al (2001) The war for talent, (Boston Massachusetts: Harvard Business School Press), pp 19-39

${ }^{25}$ Kaye, B., and Jordan-Evans, S., (1999) Love 'em or lose 'em: getting good people to stay, (San Francisco: Berrett-Koehler Publishers), p 9

${ }^{26}$ Sirota, D., et al., (2005) The enthusiastic employee (Upper Saddle River, New Jersey: Wharton School Publishing), p 9.
} 
essential to give your staff a sense of achievement both in terms of their own contribution and daily work activities but also in the company as a whole.

The final element is camaraderie. The need to work with co-workers who are reasonable, competent and supportive is a basic requirement of most employees. When teams and groups work well they can deliver exceptional results. The converse is also true with dysfunctional work groups who can cause major issues to the smooth running and harmony of an organization.

\section{Innovation}

If innovation is to yield the much needed results organizations seek, what is the best way to focus your innovation efforts? What is required is a strategy for innovation and according to Chartic ${ }^{27}$ this can be achieved by combining the two principal elements of solution-based innovation (which involves introducing superior and highly defensible solutions to known market needs) and need-based innovation (which involves redefining market requirements based on fresh insights into the unspoken and more fundamental needs of the customer). Combining both is possibly the only way to avoid the me-too hell of commoditization. The two-by-two model which comes from combining these two critical dimensions is as follows:

- Where the solution is defensible and the market need well known, solution-based innovation is the best strategy to adopt. This is where the unmet, but known needs of the market can be targeted with superior solutions that are both cost effective and of significant value to the customer

- Where the solution is defensible but the market need unspoken, then the approach should be one of changing the game. In this strategy the focus is on uncovering a fundamental market need and then developing highly defensible solutions to that need.

- Where the solution is generic and the market need well known then you are in what Chartic terms, me-too hell. Most companies want to escape this commodity trap, but there are an increasing number who recognise this is where they are likely to stay and plan accordingly.

- Where the solution is generic and the market need unspoken then the strategy is one of need based innovation which involves getting to the fundamental market need. This is never easy because it involves getting under the skin of the customer and really understanding what their needs are.

In responding to the impacts of commoditization and me-too hell, organizations are also turning to their customers to actively engage them in the process of innovation. Such outside innovation involves engaging directly with lead users and key customers to harness and commercialise their ideas and more importantly to co-design solutions that will better meet their needs ${ }^{28}$. This approach to innovation allows companies to avoid many of the problems that beset the traditional approaches including creating products which have little connection with the customer's real problems, sales staff presenting solutions instead of uncovering needs and customer services failing to pick up some of the hidden problems that require solutions ${ }^{29}$.

With innovation taking centre stage in an increasingly commoditized world, the ability to both harness the internal talents of your staff and to engage your customers

\footnotetext{
${ }^{27}$ www.chartic.com, avoiding the black hole of commoditization

${ }_{28}$ Seybold, P., (2006) Outside innovation: how your customers will co-design your company's future, (New York: Collins), p 3.

${ }^{29}$ Thull, J., (2005) Value creation: the new core competency, marketingProfs.com
} 
in developing products and solutions that will genuinely make a difference is becoming critical.

\section{Branding}

Although some believe that the brand has had its day and consumers should be less concerned about brands than they used to, the results of experiments by neuroscientists suggest that branding is still a very powerful force. When researchers scanned the brains of subjects exposed to images of brands they discovered that strong ones excited parts of the brain most associated with pleasure and reward. Other findings were equally intriguing, especially one which suggested that brain activity for an action seems to begin about half a second before a person decides to take the action. This suggests that we do not make decisions but become aware of a decision which has already been made ${ }^{30}$. All this has got the advertisers and brand management experts salivating because it means they might be able to control how consumers behave - the way they want them to.

Branding can also help to avoid some of the more obvious problems associated with commoditization, such as price sensitivity. Take salt for example. Salt is one of the most basic of commodities and is both abundant and cheap to purchase. Despite this, Morton, a US salt provider is able to charge more for its salt than any of its competitors and has been able to increase its market share to 50 per cent. Successfully branding its salt, which comes in a blue canister with a girl with an umbrella on it and the promise that rain won't damage its pourability, has been key to its success ${ }^{31}$. The lesson here is that if it is possible to differentiate salt through branding then it ought to be possible to differentiate other products and services through branding too. In fact branding can turn small product and service differences into significant advantages, especially when coupled with a high sales volume. Companies such as Intel, Gillette and Campbell have all leveraged their brands and succeeded despite the highly competitive and commoditized markets in which they operate. Thus suggests that with the appropriate focus and investment in their brand a company can be extremely successful in a commoditized market where despite the competition, it can still be relatively simple to stand out from the crowd.

Just as it is possible to follow the standard rules of branding and to follow the pack, it is also possible to do the opposite and succeed by taking a completely different direction. This often means going against the received wisdom, but it can pay off ${ }^{32}$. Scion, Toyota's youth-focused small car brand broke its 150,000 sales target in 2006 by 25,000 . Instead of ramping up sales for 2007 they made the conscience decision to pare sales and production back to no more than 150,000 in order to keep the brand special, even though the belief was that they could have surpassed 250,000 cars without much problem. Not just that, but they are also reducing spend on advertising, already quite low by industry standards and may eliminate it altogether in a bid to create an "underground" brand. They are also going one step further, as they will focus their marketing at the experiential level which will include branded entertainment following the success of the Scion music label for emerging artists and its own clothing line called Scion Release.

\section{A final comment - the importance of organizational culture}

\footnotetext{
${ }^{30}$ Mitchell, A., (2007) Advertisers turn to science to get inside consumers' heads, Financial Times, January 5, p 10.

${ }^{31}$ Surwiecki, J., (1998) The commoditization conundrum, slate.msn.com

${ }^{32}$ Ries, A., and Ries, L., (2004), The origin of brands, (New York: HarperCollins), p 139
} 
We should never underestimate the power that culture, in all its forms, has over us. Whether we are talking about national culture or team culture, each will impact the way we behave, interact with other people and defines at least to some extent, our preferences.

Interest in culture in general and organizational culture specifically has gained ground within academic and business circles alike. However, for many employees and senior executives it still remains a mystery which is typically encapsulated in the phrase the way we do things round here. In contrast for those who have taken the trouble to unravel it, it can be a powerful tool in the organization's arsenal. The reason why culture is so powerful is that it provides the necessary glue which keeps everyone aligned and engaged and it helps to build the norms of behaviour which make a company what it is. Although it is well known that a strong culture has a positive impact on performance, if it is too strong it can make it very difficult and indeed painful to adapt to changing circumstances. Before it had to transform itself, IBM had a very strong culture even down to the dress code - the ubiquitous white shirt and dark suit. This culture served it well and ensured IBM's image, reputation and brand were well known and relied upon. The problem, however, was this created a degree of arrogance, which often happens with the market leaders and prevented them from spotting the obvious changes in the way computers were being used. It took a lot of effort to change the culture so that the business was able to respond to the changing demands and expectations.

The lessons from IBM and others which have had to react to similar market conditions is that the culture of a corporation increasingly needs to be adaptive to the changes that will inevitably occur over the foreseeable future as commoditization takes on a greater significance. Such adaptability will necessitate a healthier attitude to change and being willing to recognise that the mix of skills, capabilities and competencies of the employees will need to adapt to the changing market and competitive conditions. This is not easy because it requires sensitivity and open communication so that every stakeholder is engaged in the process and it requires a culture that is able to absorb change more effectively.

We have reviewed a number of areas which should form a response when addressing the challenge of commoditization. What is important amongst all this is that the response has to be consciously defined and cannot be entirely tactical. Naturally the choices you make will depend on whether you wish to operate within a commoditized environment or to avoid it as much as possible. It should also be remembered that there are already plenty of organizations that are very successful in operating in highly competitive, cost focused markets, which means avoidance may not always be the best strategy. 